\title{
Model Test On The Settlement Controlling Effect Of New CFG Pile-board Structure Composite Foundation Based On Similar Theory
}

\author{
Dingbang Zhang ${ }^{1,2, a}$, Weng Ling ${ }^{1, b}$ \\ ${ }^{1}$ School of Civil Engineering, Hubei Polytechnic University, Huangshi, Hubei, 435003, China \\ ${ }^{2}$ Faculty of Engineering, China University of Geoscience, Wuhan, Hubei, 430074, China \\ a6076961@qq.com, b596009717@qq.com
}

Keywords: similar theory, model test, pile-board structure, settlement.

\begin{abstract}
Based on the similar theory of physical model test, the similarity ratio of physical and mechanical parameters is derived for model test. The similarity ratio were used in model test of new CFG pile-board structure composite foundation to study the settlement controlling effect and settlement distribution character of Beijing-Shanghai high speed railway. The results show that new CFG pile-board structure composite foundation can effectively control the settlement of subgrade.
\end{abstract}

\section{Introduction}

Composite foundation technique has been widely used in civil engineering related fields such as water conservancy engineering, construction, transportation engineering and municipal engineering, especially building highway, railway, large-scale oil tanks and deep excavation in the deep soft soil foundation of coastal regions, the composite foundation technology has got rapid development. The new type of CFG pile-board structure is a special composite foundation technique dealing with soft soil foundation to controlling the settlement of high-speed railway. It is constituted by CFG pile, reinforced concrete pile and reinforced concrete board[1,2]. The edge of each reinforced concrete board is connected and supported by reinforced concrete pile into a line, and the middle of each reinforced concrete board is connected and supported by CFG pile into a square (Fig .1). In this paper, the similarity ratio of new CFG pile-board structure model test are derived according to the similarity ratio, the settlement controlling effect of new CFG pile-board structure composite foundation are studied for engineering reference.

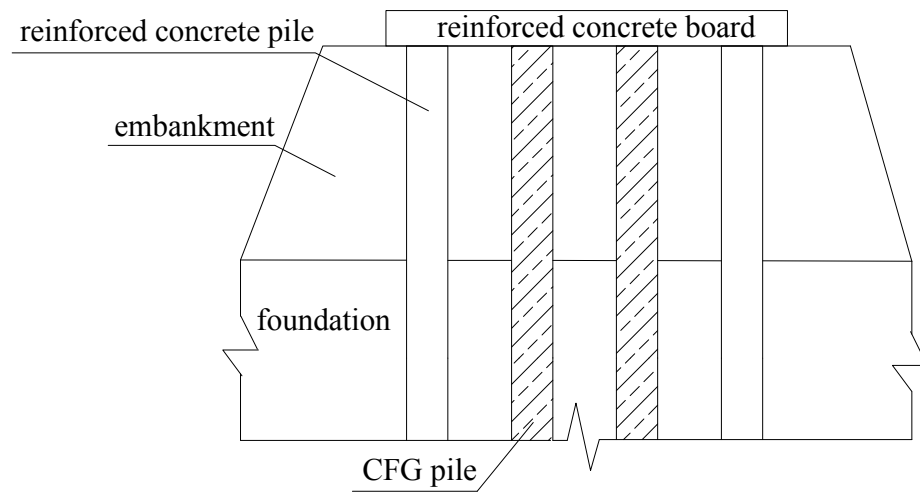

Fig.1 Schematic of CFG pile-board structure

\section{Derivation of similarity ratio}

The similar conditions consist of geometric conditions, physical condition, boundary conditions and initial conditions. All the conditions must meet the requirements of model test. The stress of CFG pile-board structure related to the geometry size, material density, elastic modulus, poisson's ratio, line load, surface load, displacement, strain and ultimate bearing capacity, so the structure stress, displacement and other variables can be expressed as the following formula: 


$$
f(\sigma, F, q, \gamma, l, E, \mu, p, S)=0
$$

At the formula, $\mathrm{F}$ is surface load, $\mathrm{q}$ is line load, $\gamma$ is material density, $\mathrm{L}$ is geometry size, $\mathrm{E}$ is elastic modulus, $\mu$ is poisson's ratio, $\mathrm{p}$ is reinforcement ratio, $\sigma$ is structure stress and $\mathrm{S}$ is displacement.

There are nine irrelevant variables in formula.1, the dimensionless analysis is used to choose two independent variables and get 7 dimensionless variables.

$$
\begin{aligned}
& \Pi_{1}=\frac{p}{F^{a_{1}} l_{1}^{b_{1}}}, \Pi_{2}=\frac{\mu}{F^{a_{2}} l_{2}^{b_{2}}}, \Pi_{3}=\frac{E}{F^{a_{3}} l^{b_{3}}}, \Pi_{4}=\frac{\gamma}{F^{a_{4}} l^{b_{4}}}, \\
& \Pi_{5}=\frac{q}{F^{a_{5}} l^{b_{5}}}, \Pi_{5}=\frac{\sigma}{F^{a_{6}} l^{b_{6}}}, \Pi_{6}=\frac{S}{F^{a_{7}} l^{b_{7}}}
\end{aligned}
$$

Firstly, the first dimensionless variables is calculated for $p$ is dimensionless factor.

$$
\begin{array}{ll}
{[0]=\left[M L T^{-2}\right]^{a}{ }^{1}[L]_{1}^{b}} \\
\left.\begin{array}{ll}
M & a_{1}=0 \\
L & a_{1}+b_{1}=0 \\
T & -2 a_{1}=0
\end{array}\right\}
\end{array}
$$

Solution of formulas:

$$
a_{1}=0, \quad b_{1}=0, \quad \Pi_{1}=p
$$

Other similarity criterion are calculated in the same way.

$$
\Pi_{2}=\mu, \Pi_{3}=\frac{E l^{2}}{F}, \quad \Pi_{4}=\frac{\gamma l^{3}}{F}, \quad \Pi_{5}=\frac{q l}{F}, \quad \Pi_{6}=\frac{\sigma l^{2}}{F}, \quad \Pi_{7}=\frac{S l}{F}
$$

Then the formula of all the similarity criterion is concluded.

$$
f\left(F, l, p, \mu, \frac{E l^{2}}{F}, \frac{\gamma l^{3}}{F}, \frac{q l}{F}, \frac{\sigma l^{2}}{F}, \frac{S l}{F}\right)=0
$$

According to the " $a_{E}=a_{\sigma}=1$ ", the following conclusions are made in Table. 1

Table.1 Similar constant chart of model experiment

\begin{tabular}{|c|c|c|c|}
\hline Physical quantity & Similar constant & Physical quantity & Similar constant \\
\hline Geometry size & $a_{l=25}$ & stress & $a_{\sigma=1}$ \\
\hline Material density & $a_{\gamma=1}$ & Surface load & $a_{F=625}$ \\
\hline Elastic modulus & $a_{E=1}$ & Displacement & $a_{s=25}$ \\
\hline Poisson's ratio & $a_{\mu=1}$ & Strain & $a_{\varepsilon=1}$ \\
\hline $\begin{array}{c}\text { Reinforcement } \\
\text { ratio }\end{array}$ & $a_{p=1}$ & $\begin{array}{c}\text { Ultimate bearing } \\
\text { capacity }\end{array}$ & $a_{R=625}$ \\
\hline Line load & $a_{q=25}$ & - & - \\
\hline
\end{tabular}

\section{Model test}

Figure 2 are typical survey area of the prototype of CFG pile-board structure model test. The survey area is half width of a typical section. CFG pile, reinforced concrete pile and reinforced concrete board are all on entity modeling, pile end are located in stability soil layer, the breadth of the board are consistent with the simulation subgrade.

According to prototype of CFG pile-board structure model test and similar ratio of the model test $(1: 25)$, so the size of model is $1300 \mathrm{~mm}$ (length) $\times 500 \mathrm{~mm}$ (width) $\times 1000 \mathrm{~mm}$ (height), pile diameter is $2 \mathrm{~cm}$, the pile length is $30 \mathrm{~cm}$ and the size reinforced concrete board is $400 \mathrm{~mm} \times 28 \mathrm{~mm} \times 500 \mathrm{~mm}$.

Side and bottom of the model are constrained by the horizontal and vertical board. The maintenance and production of all the model parts are in standard way. The loading equipment of the 
model test is oil jack. Five static load model tests of new type of CFG pile-board structure composite foundation are studied.

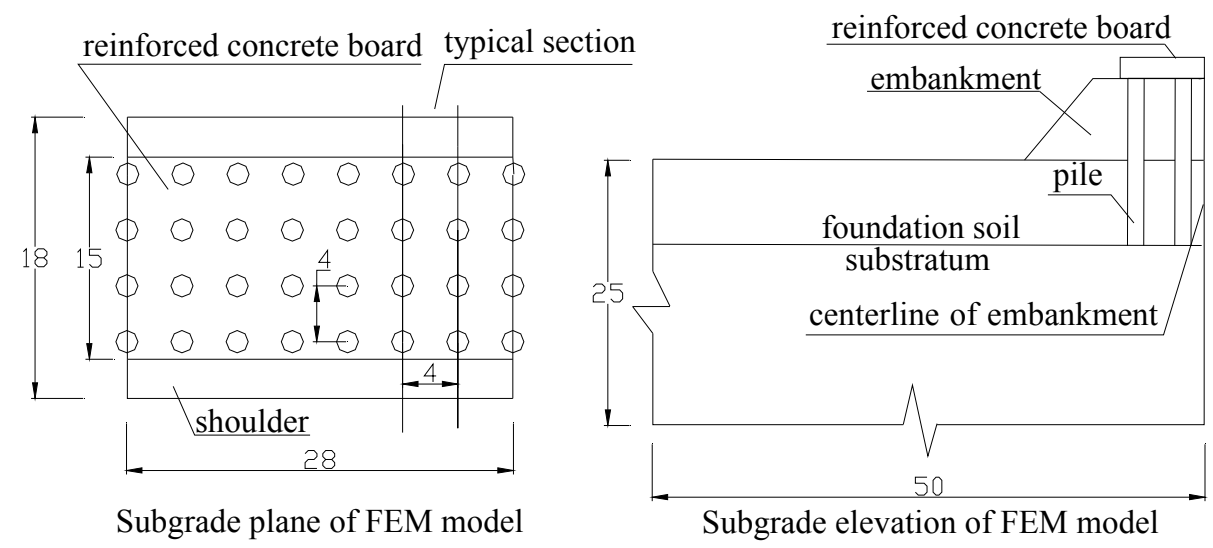

Fig.2 Prototype of CFG pile-board structure model test(unit:m)
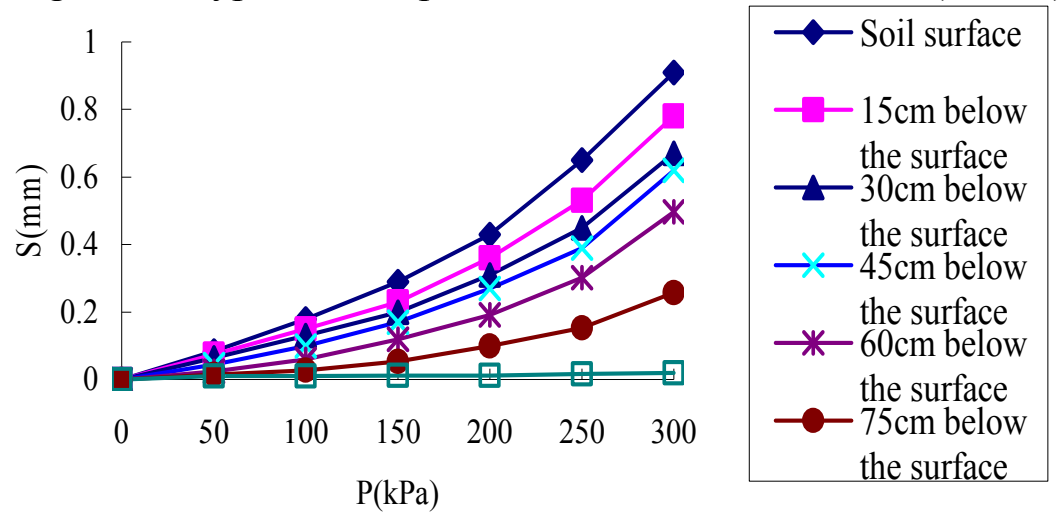

Fig.3 The p-s curve of pile-board composite foundation

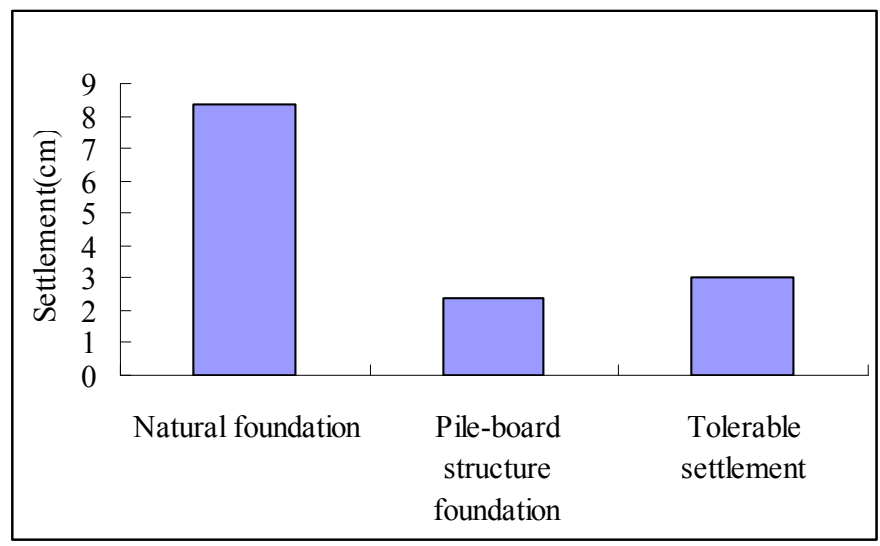

Fig.4 The contrast picture of ground subsidence when $\mathrm{p}=300 \mathrm{kPa}$

\section{Result analysis}

The p-s curve of pile-board composite foundation(Fig.3) show that the settlement in different depth of composite foundation increase linearly while the load is under $200 \mathrm{kPa}$, the CFG pile-board structure is in elastic deformation stage. While the load exceed $200 \mathrm{kPa}$, the settlement in different depth of composite foundation increase nonlinearity, the CFG pile-board structure is in a transition stage from elastic to plastic deformation and the critical load of test model is $200 \mathrm{kPa}$.

In the whole test process, the settlement of CFG pile-board structure composite foundation is increasing with the the increasing load. At the beginning of loading, the external load is small, the reinforced effect of CFG pile-board structure in composite foundation isn't obviously, the foundation soil bear most of the external load. With the load increasing, the soil between the pile are compacting, Interaction between pile and soil also gradually strengthening, the CFG pile-board structure gradually 
play a important role in reinforcing the foundation, the pile bear more and more external load, the settlement controlling effect are more and more obvious. From the settlement contrast of natural ground subsidence and CFG pile-board structure composite foundation (Fig.4), it shows that the maximum settlement of natural ground is $2.35 \mathrm{~cm}$ (less than tolerable settlement of high speed railway) when $\mathrm{p}=300 \mathrm{kPa}$. it concluded that adopting $\mathrm{CFG}$ pile-board structure to improve the working characters of soil and reduce embankment settlement has remarkable effect. By way of model based on similar theory, it shows that the new CFG pile-board structure theory can be generalized in engineering practice.

\section{Conclusions}

By means of adopting similar theory to build a model of new CFG pile-board structure composite foundation, the settlement controlling effect of the composite foundation is studied. The main conclusions are as follows:

The indoor model test of new type of CFG pile-board structure composite foundation is a effectively technique with advantages of small investment, short period, low cost and simple structure.

This model test based on similarity theory can effectively reflect the real state of experiment prototype, the research results are reliable.

From the research of model test, it concluded that adopting CFG pile-board structure to improve the working characters of soil and reduce embankment settlement has remarkable effect.

\section{Acknowledgment}

The authors gratefully acknowledge the support of Teaching Research Project of Hubei Polytechnic University (Grant No. 201017) in this study.

\section{References}

[1] Zuo Dong-Qi. (1984). The theory and method of the model test. Beijing: China WaterPower Press, edition.1:5-23.

[2] Niu Guo-Hui, Jiang Guan-lu, Zhan Yong-Xiang, Wei Yong-Xing. (2007). Study on big scale dynamic model test of pile_plane subgrade of Suining-Chongqing ballastless track railway. Railway construction technology,october,41-43.

[3] Yang Jun-Jie (2005). Similarity theory and structure model test. Wuhan: Wuhan university of science and technology press,29-31.

[4] Yang Guang-Qing, Liu Shu-Shan, liu Tian-Ming. (1999). Design and construction of high speed railway roadbed. China railway publishing house,17-18.

[5] Ding Zhao-Feng, Su Qian, Cui Wei-Xiu. (2008). Test of Embedded Continuous Pile-Board Structure in Zhengzhou-Xi an Passenger Dedicated Line. Subgrade engineering. January, 38-40. 